\title{
Navier-Stokes Analysis and Experimental \\ Data Comparison of Compressible Flow Within Ducts
}

\author{
G.J. Harloff
}

Sverdrup Technology, Inc.

Lewis Research Center Group

Brook Park, Ohio

B.A. Reichert

National Aeronautics and Space Administration

Lewis Research Center

Cleveland, Ohio

J.R. Sirbaugh

Sverdrup Technology, Inc.

Lewis Research Center Group

Brook Park, Ohio

and

S.R. Wellborn

Iowa State University

Ames, Iowa

Prepared for the

13th International Conference on Numerical Methods in Fluid Dynamics

Rome, Italy, July 6-10, 1992 
duct cross section in the $y z$-plane changes from circular to nearly rectangular in the region $1.0 \leq x / D_{1} \leq 2.5$. The duct aspect ratio (the ratio of the major to minor axis lengths at $x / D_{1} \geq 2.5$ ) is 3.0 . The cross-sectional areas at $x / D_{1} \leq 1.0$ and $x / D_{1} \geq 2.5$ are equal. In the region $1.0 \leq x / D_{1} \leq 2.5$ the cross-sectional area increases as much as 1.15 times the area at $x / D_{1} \leq 1.0$.

\section{Experiment}

The inlet diameter of both the S-duct and transition duct was $10.24 \mathrm{~cm}$. The $S$-duct is larger and geometrically similar to the duct studied by Vakili $e t$ $a .^{2}$ The transition duct is identical to that of Davis and Gessner. The inlet conditions for both ducts are summarized in Table 1. For the transition duct experiment with swirling flow, the maximum swirl angle was $15.6^{\circ}$. A swirl generator was used to produce solid body rotation with minimal downstream disturbances. Additional information about the experimental programis contained in Refs. 7, 8.

Detailed measurements of velocity, total pressure, and static pressure were made at cross-stream planes inside both ducts with calibrated three- and five-hole probes. Data were acquired at about 530 locations near the $\mathrm{S}$-duct inlet (at $s / D_{1}=-0.5$ ) and at nearly 1220 locations near the $S$-duct exit (at $\left.s / D_{1}=5.73\right)$. In the transition duct, measurements were made in four cross-stream planes located at $x / D_{1}=1.49,1.99,2.55$, and 3.93 . The measurements were acquired at approximately 480 locations in each measurement plane. Surface oil film visualization and surface static pressure measurements were also obtained for both ducts.

Table 1 Experimental inlet conditions.

\begin{tabular}{lccc} 
& S-duct & \multicolumn{2}{c}{ Transition duct } \\
& & No swirl & Swirl \\
\cline { 2 - 4 }$M_{\text {centerline }}$ & 0.60 & 0.50 & 0.35 \\
$\operatorname{Re}_{D_{1}} \times 10^{-6}$ & 2.20 & 2.09 & 1.37 \\
$\delta_{0.95} / D_{1} \times 100$ & 3.04 & 3.76 & 10.24
\end{tabular}

\section{Computation}

The PARC3D computer program solves the full, three-dimensional Reynolds-averaged Navier-Stokes equations in strong conservation form with the Beam and Warming approximate factorization algorithm. The implicit scheme uses central differencing for a curvilinear set of coordinates. Ref. 9 describes in detail the theory and features of the PARC code.

A Baldwin-Lomax ${ }^{10}$ algebraic turbulence model was used. The model was modified to use only vorticity in the local boundary layer to avoid secondary flow effects on the eddy viscosity. "The turbulence model was also modified for the swirling flow transition duct computation to remove the constant level of axial vorticity from the vorticity level in the boundary layer. For the $S$-duct computation a low-Reynolds number $k-\epsilon$ turbulence model of Speziale et al. ${ }^{12}$ was also used. The numerical solution algorithm is that of Nichols. ${ }^{13}$

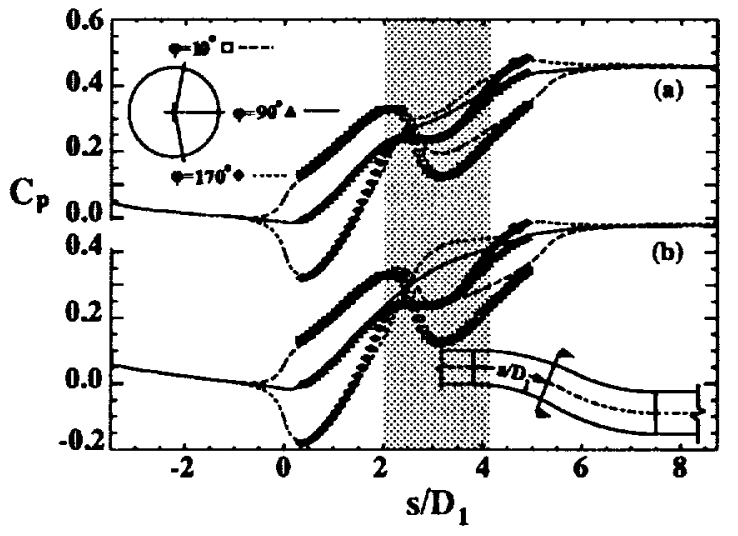

Fig. 3 Surface static pressure coefficlent for S-duct flow, (a) $\boldsymbol{k}-\boldsymbol{\epsilon}$ turbulence model, (b) algebralc turbulence model.

The S-duct grid was composed of three blocks with grid distributions of $32 \times 71 \times 53,69 \times 71 \times 53$, and $32 \times 71 \times 53$. An H-grid of $129 \times 11 \times 15$ was used in the center. Gridgen ${ }^{14}$ was used to define the interior grid. The first point off the wall had an average $y^{+}$of less than 1 . The boundary conditions were no slip at the walls, total pressure and temperature specified at the entry plane, static pressure specified at the exit plane, and symmetry about the $x z$-plane.

For nonswirling transition duct flow the grid modeled one duct quadrant and contained $97 \times 51 \times 53$ grid points. The inlet total temperature and pressure were specified locally. At the duct exit, a constant static pressure was specified and density and velocity were extrapolated from the interior. The downstream static pressure was adjusted to match the measured surface static pressures at the inlet. The swirling flow transition duct computation was performed with a $97 \times 51 \times 97$ grid that modeled two duct quadrants. New boundary conditions were incorporated in the PARC code to permit swirling inlet flow and to accommodate the $180^{\circ}$ rotational symmetry of the flow. For the swirl case, the inlet boundary condition used the experimentally measured inlet flow angles.

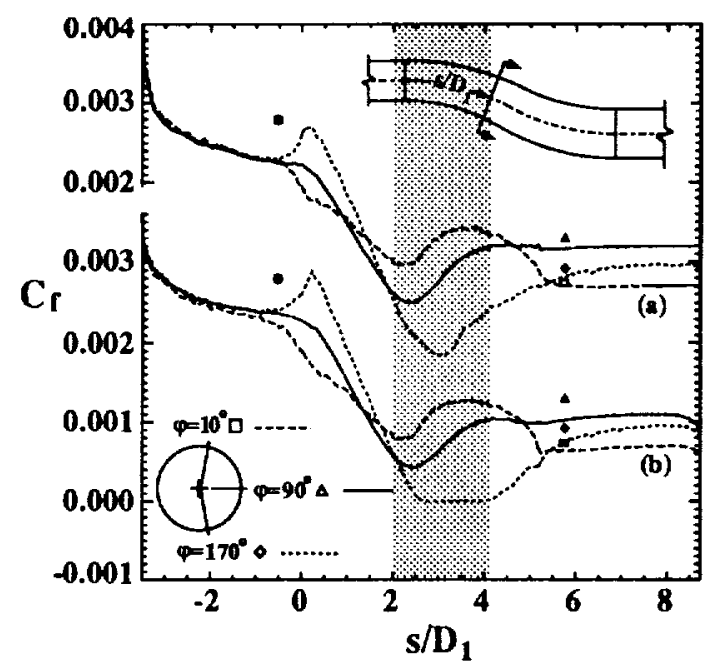

Flg. 4 Skin friction coefficient for S-duct flow, (a) $k-\epsilon$ turbulence model, (b) algebraic turbulence model. 

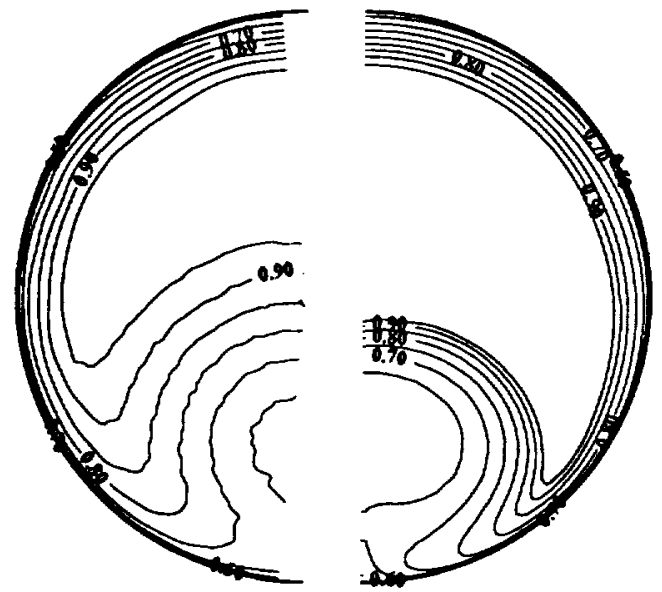

(a)

Experiment

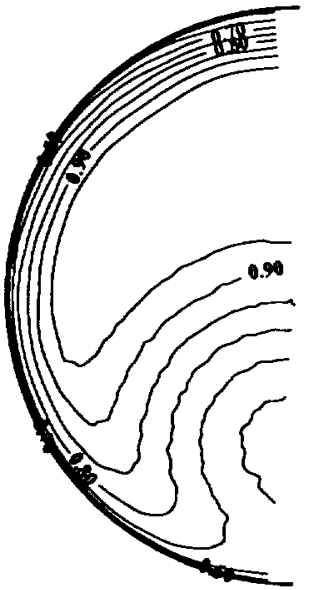

(b) Experiment

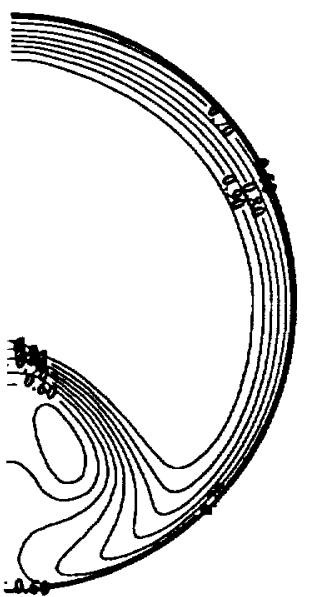

Computation

\section{Computation}

Fig. 5 Exit plane total pressure coefficient for S-duct flow, (a) $\boldsymbol{k}-\boldsymbol{\epsilon}$ turbulence model, (b) algebraic turbulence model.

Results and Discussion

The total and static pressures in this section are presented as pressure coefficients given by Eq. (1). The pressures $p_{0}$ and $p$ represent the local total and static pressure. The reference variables, subscripted $\mathrm{cl}$ (centerline) or wall, were evaluated at one-half inlet diameter upstream of the $\mathbf{S}$-duct or transition duct inlet (at $s / D_{1}=-0.5$ or $x / D_{1}=-0.5$ ).

$$
C p_{0}=\frac{p_{0}-p_{w a l l}}{p_{0, c l}-p_{w a l l}}, \quad C p=\frac{p-p_{w a l l}}{p_{0, c l}-p_{w a l l}}
$$

Diffusing S-Duct Results

The computed and experimental surface static pressure distributions are shown in Fig. 3. Both the algebraic and $k-\epsilon$ turbulence model results agree with the experimental values upstream of the experimentally determined separation (shaded region in Figs. 3 and 4). In the separation zone, the $k-\epsilon$ model agrees better with experimental values, and downstream of separation both models begin to agree with the experimental data. Predicted and experimental skin friction coefficient values are plotted in Fig. 4. The agreement is considered reasonable. The experimentally measured region of flow

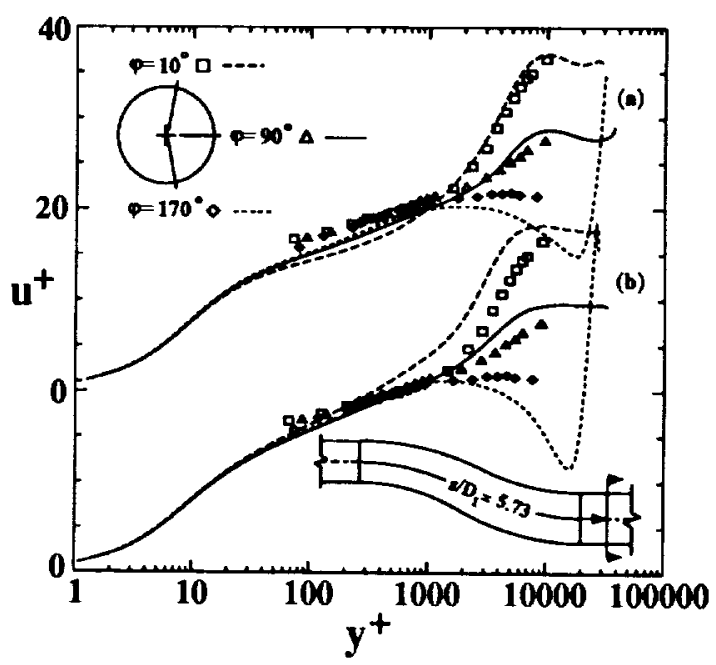

Flg. $6 \mathrm{Law}$ of the wall velocity profiles for flow near $S$-duct exit, (a) $k-\epsilon$ turbulence model, (b) algebraic turbulence model.

separation is $2.02 \leq s / D_{1} \leq 4.13$. The $k-\epsilon$ and the algebraic turbulence models predict separation between $2.59 \leq s / D_{1} \leq 4.25$ and $2.69 \leq s / D_{1} \leq 4.25$, respectively. The computational values were determined

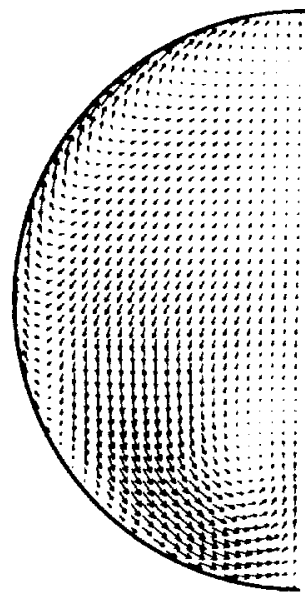

(a) Experiment

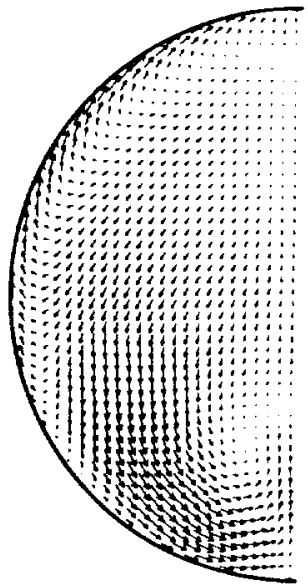

(b) Experiment

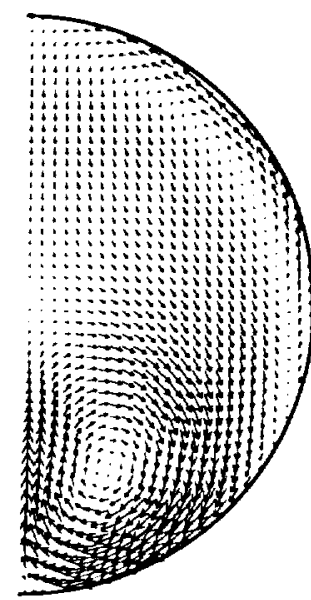

Computation

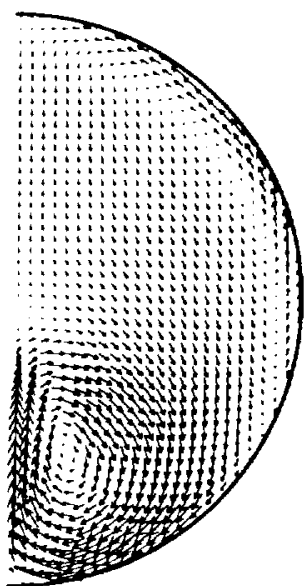

Computation
Fig. 7 Exit plane transverse Mach vector components for S-duct flow, (a) $k-\epsilon$ turbulence model, (b) algebraic turbulence model. 


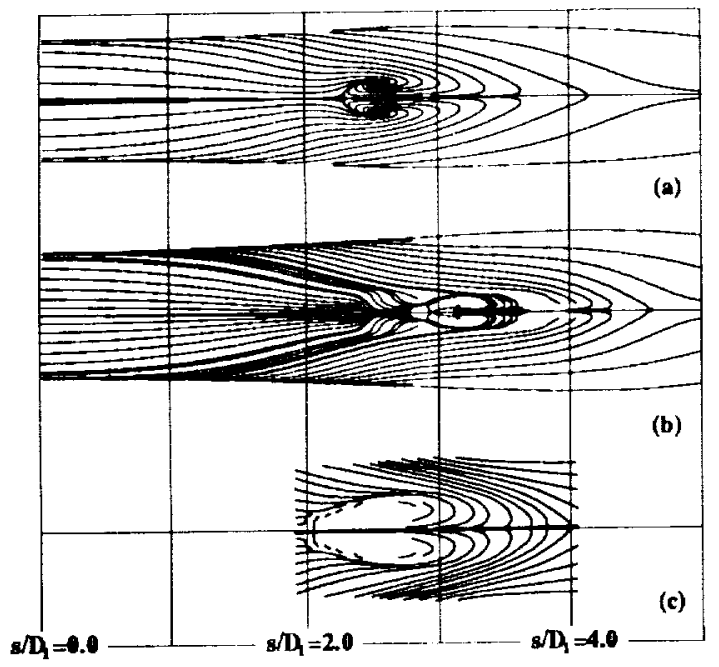

Fig. 8 Near surface flow visualization,

(a) $\boldsymbol{k}-\boldsymbol{\epsilon}$ turbulence model, (b) algebraic turbulence model, (c) experiment.

from locations of negative axial velocity at the grid point nearest the wall along $\phi=180^{\circ}$.

Computational and experimental total pressure contours near the S-duct exit $\left(s / D_{1}=5.73\right)$ are compared in Fig. 5. The predicted region of diminished total pressure is smaller than the measured region for both turbulence models. This discrepancy is possibly due to a turbulence modeling deficiency to account for with strong cross flow (three-dimensional) effects or a modeling deficiency of artificial viscosity in the boundary layer separation region. The grid resolution should be adequate as the distance of the first grid point off the wall is approximately $y^{+}$of 1 .

The predicted velocity profiles for both turbulence models near the S-duct exit are shown in wall coordinates in Fig. 6. Near the S-duct exit the vortices have convected low velocity fluid away from the wall and the boundary layer in this region, particularly at $\phi=170^{\circ}$, departs significantly from this law.

Experimental and computed transverse velocity vectors are shown in Fig. 7 near the duct exit. The results show the presence of large counter-rotating vortices in the lower half of the cross section. Both computations are in qualitative agreement with the experiment.

The predicted streamlines in the region of flow separation are compared with the surface oil film visualization in Fig. 8. The predicted flow fields are in general agreement with the data, and the $k-\epsilon$ turbulence model streamlines better compare to the experimental streamlines.

Circular-to-Rectangular Transition Duct Results

The numerical and experimental values of surface static pressure for both the nonswirling and swirling flow cases are plotted in Fig. 9. The prediction is very good indicating that the actodynamic blockage is correctly predicted. Experimental and computed contours of the total pressure coefficient at $x / D_{1}=2.55$ are shown in Fig. 10 (a) for flow without inlet swirl. The concentric contours extending inward from the duct side walls are regions of diminished total pressure that result from

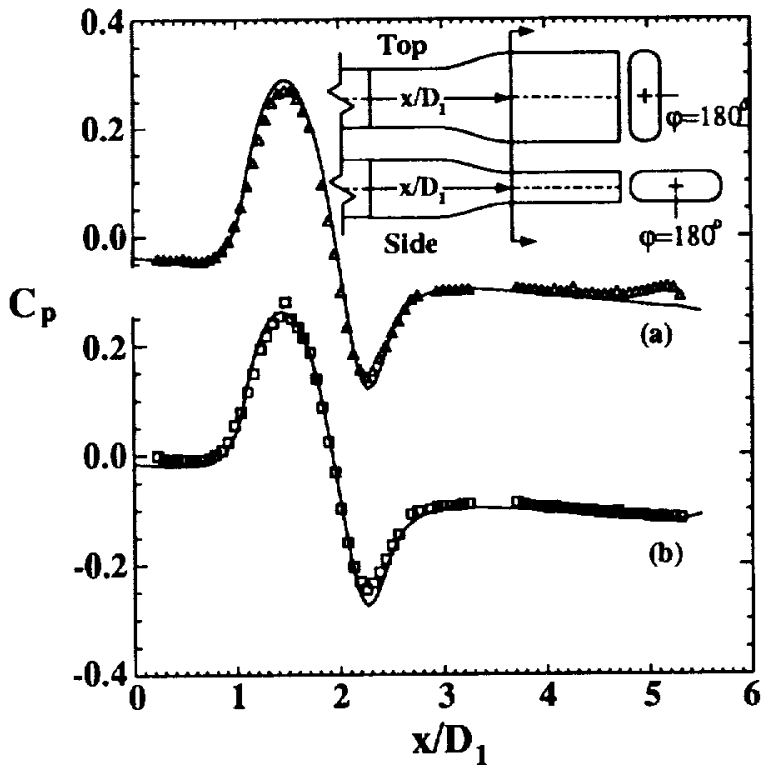

Fig. 9 Surface static pressure coefficient for transition duct flow, (a) without inlet swirl, (b) with inlet swirl.

side wall vortices convecting low total pressure fluid away from the duct surface. This is the most upstream location where the effects of the side wall vortices are noticeable in the experimental data. The numerical results predict the same flow structure at $x / D_{1}=2.55$, but the region of diminished total pressure is not as large as the experimental results reveal.

Total pressure contours at $x / D_{1}=3.93$, Fig. 10 (b), also show the predicted region of diminished total pressure does not extend as far from the side walls as was experimentally observed. Comparing experimental and numerical surface flow visualization indicates that the point of formation of the vortices is correctly predicted. This suggests that the turbulence model, restricted to wall bounded shear flow, can not account for turbulent mixing in the vortex region. The agreement outside the region affected by the side wall vortices at $x / D_{1}=2.55$ and 3.93 is excellent.

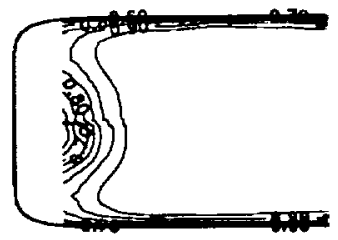

(a)

Experiment
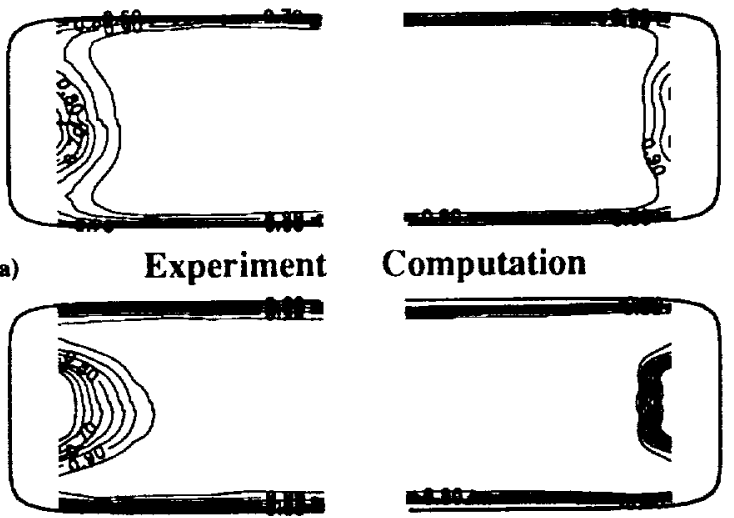

Computation

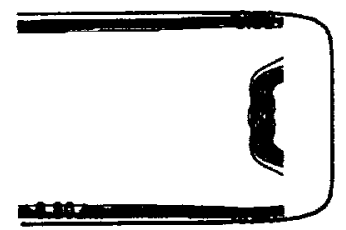

(b)

Experiment Computation

Fig. 10 Total pressure coefficient for transition duct flow without inlet swirl, (a) at $x / D_{1}=2.55$, (b) at $x / D_{1}=3.93$. 

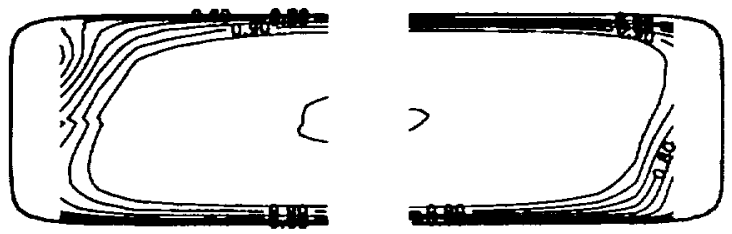

(a)

Experiment

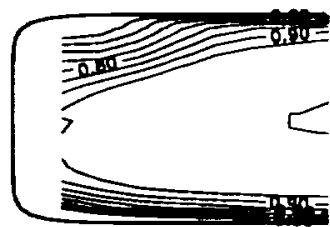

(b)

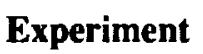

Computation

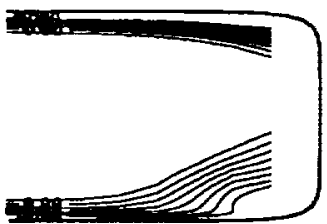

Computation

Fig. 11 Total pressure coefficient for transition duct flow with Inlet swirl, (a) at $x / D_{1}=2.55$, (b) at $x / D_{1}=3.93$.

The total pressure at $x / D_{1}=2.55$ and 3.93 for flow with inlet swirl are shown in Figs. 11 (a) and (b). With swirl the flow is symmetric with respect to $180^{\circ}$ rotations about the $x$-axis. Regions of diminished total pressure near the duct side walls (that were produced in the nonswirling flow by the side wall vortices) are absent. However, surface oil film visualization, Ref. 7, indicates cross flow near the duct corners in the downstream region of the duct. The effect of the cross flow on the total pressure coefficients is visible, particularly in the upper left (experiment) and lower right (computation) quadrant at $x / D_{1}=2.55$. In general, the agreement between the experiment and computation is better for the swirling case (no side wall vortices) than the nonswirling case (side wall vortices). This is most apparent at $x / D_{1}=3.93$ where the comparison in Fig. 11 (b) is noticeably better than Fig. 10 (b).

\section{Conclusion}

The PARC3D Navier-Stokes code has been used to compute flow through a diffusing $S$-duct and a circularto-rectangular transition duct with and without inlet swirl. The objective of these calculations was to assess the ability of the PARC code to accurately predict flows through propulsion system ducts. The S-duct computed flow fields are generally in good agreement with the experimental data. However, both turbulence models underpredict the length and angular extent of the boundary layer separation, and the predicted separation occurs one half $s / D_{1}$ late. Neither algebraic nor $k-\epsilon$ turbulence model adequately accounts for strong secondary flows with separation. The transition duct flow field matched the experimental total and surface static pressure coefficients well. The agreement appeared better for flow with inlet swirl, where the pairs of counter-rotating vortices at the duct exit were absent. For attached flow, PARC3D has demonstrated reasonable accuracy. For flows with strong cross flow and or with separated boundary layers, the modeled turbulence and or artificial viscosity should be improved.

\section{Acknowledgment}

The CFD effort of this investigation was supported by NASA Lewis Research Center under contract No. NAS3-25266. The computations were carried out on the NASA Lewis YMP computer. The authors would like to thank Mr. J. Bruns, Mr. R. Burley, Dr. W. Hingst, Dr. K. Kirtley, Mr. J. Kerouac, Prof. T. Okiishi, Mr. C. Smith and Dr. B. Wendt for their advice and assistance.

\section{References}

${ }^{1}$ Bansod, P. and Bradshaw, P., "The Flow in S-shaped Ducts," Aeronautical Quarterly. Vol. 23, May 1972, pp. 131-140.

${ }^{2}$ Vakili, A. D., Wu, J. M., Liver, P., and Bhat, M. K., "Experimental Investigation of Secondary Flows in a Diffusing S-Duct," The University of Tennessee Space Institute Tech. Rep. UTSI 86/14, 1984.

${ }^{3}$ Sobota, T. H. and Marble, F. E., "Swirling Flows in an Annular-to-Rectangular Transition Section," Journal of Propulsion and Power, Vol. 5, May 1989, pp. 334-340.

${ }^{4}$ Davis, D. O. and Gessner, F. B., "Experimental Investigation of Turbulent Flow Through a Circular-toRectangular Transition Duct," AIAA Paper 90-1505, 1990.

${ }^{5}$ Smith, C. F., Bruns, J. E., Harloff, G. J., and Debonis, J. R., "Three-Dimensional Compressible Turbulent Computations for a Diffusing S-Duct," Sverdrup Technology, Inc. NASA CR 4392, 1991.

${ }^{6}$ Harloff, G. J., Smith, C. F., Bruns, J. E., and DeBonis, J. R., "Navier-Stokes Analysis of Three-Dimensional SDucts," Submitted to AIAA Joumal of Aircraft.

${ }^{7}$ Reichert, B. A., Hingst, W. R., and Okiishi, T. H., "An Experimental Comparison of Nonswirling and Swirling Flow in a Circular-to-Rectangular Transition Duct," AIAA Paper 91-0342, 1991. (also NASA TM 104359). ${ }^{8}$ Wellbom, S. R., Reichert, B. A., and Okiishi, T. H., "Aerodynamic Measurement of the Subsonic Flow Through a Diffusing S-Duct," AIAA Paper 92-3622, 1992.

${ }^{9}$ Cooper, G. K., "The PARC Code: Theory and Usage," A.E.D.C. Tech. Rep. TR-87-24, Oct. 1987.

${ }^{10}$ Baldwin, B. S. and Lomax, H., "Thin Layer Approximation and Algebraic Model for Separated Turbulent Flows," AIAA Paper 78-257, 1978.

"Sirbaugh, J. R. and Reichert, B. A., "Computation of a Circular-Lo-Rectangular Transition Duct Flow Field," AIAA Paper 91-1741, 1991.

${ }^{12}$ Speziale, C. G., Ridha, A., and Anderson, E. C., "A Critical Evaluation of Two-Equation Models for Near Wall Turbulence," ICASE Tech. Rep. 90-46, June 1990.

${ }^{13}$ Nichols, R. H., "A Two-Equation Model for Compressible Flows," AIAA Paper 90-0494, 1990.

${ }^{14}$ Steinbrenner, J. P., Chawner, J. R., and Fouts, C. L., "The Gridgen 3D Multiple Block Grid Generation System," Wright Research and Development Center Tech. Rep. WRDC-TR-90-3022, July 1990. 
Public reporting burden for this collection of information is estimated to average 1 hour per response, including the time for reviewing instructions, searching existing data sources, gathering and maintaining the data needed, and compieting and reviewing the collection of information. Send comments regarding this burden estimate or any other aspect of this collection of information including suggestions for reducing this burden, to Washington Headquarters Services, Directorate for information Operations and Reports, 1215 Jefferson Davis Highway, Suite 1204, Arlington, VA 22202-4302, and to the Office of Management and Budget, Paperwork Reduction Project (0704-01B8). Washington, DC 20503.

\begin{tabular}{|l|c|c|}
\hline 1. AGENCY USE ONLY (Leave blank) & $\begin{array}{c}\text { 2. REPORT DATE } \\
\text { July } 1992\end{array}$ & $\begin{array}{r}\text { 3. REPORT TYPE AND DATES COVERED } \\
\text { Technical Memorandum }\end{array}$ \\
\hline
\end{tabular}

\section{TITLE AND SUBTITLE}

Navier-Stokes Analysis and Experimental Data Comparison of Compressible

Flow Within Ducts

5. FUNDING NUMBERS

\section{AUTHOR(S)}

WU-505-62-52

G.J. Harloff, B.A. Reichert, J.R. Sirbaugh, and S.R. Wellborn

\section{PERFORMING ORGANIZATION NAME(S) AND ADDRESS(ES)}

8. PERFORMING ORGANIZATION REPORT NUMBER

National Aeronautics and Space Administration

Lewis Research Center

E-7226

Cleveland, Ohio 44135-3191

9. SPONSORING/MONITORING AGENCY NAMES(S) AND ADDRESS(ES)

10. SPONSORING/MONITORING AGENCY REPORT NUMBER

National Aeronautics and Space Administration

Washington, D.C. 20546-0001

NASA TM-105796

11. SUPPLEMENTARY NOTES

Prepared for the 13th International Conference on Numerical Methods in Fluid Dynamics, Rome, ltaly, July 6-10, 1992. G.J. Harloff, Sverdrup Technology, Inc., Lewis Rescarch Center Group, 2001 Aerospace Parkway, Brook Park, Ohio 44142. B.A. Reichert, NASA Lewis Research Center, Cleveland, Ohio, J.R. Sirbaugh, Sverdrup Technology, Inc., Lewis Rescarch Center Group, 2001 Aerospace Parkway, Bronk Park, Ohio 441.12. S.R. Wellborn, lowa State University, Ames, lowa 50010. Responsible person, B.A. Reichert, (216) 433-8397.

12a. DISTRIBUTION/AVAILABILITY STATEMENT

Unclassified - Unlimited

Subject Category 07

13. ABSTRACT (Maximum 200 words)

Many aircraft employ ducts with centerline curvature or changing cross-sectional shape to join the engine with inlet and exhaust components. S-ducts convey air to the engine compressor from the intake and often decelerate the thow to achicve an acceptable Mach number at the engine compressor by increasing the cross-sectional area downstream. Circular-to-rectangular transition ducts are used on aircraft with rectangular exhaust nozzles to connect the engine and nozzle. To achieve maximum engine performance, the ducts should minimize flow total pressure loss and total pressure distortion at the duct exit. Changes in the curvature of the duct centerline or the duct cross-sectional shape give rise to streamline curvature which cause cross stream pressure gradients. Secondary flows can be caused by deflection of the transverse vorticity component of the boundary layer. This vortex tilting results in counter-folating vortices. Additionally the adverse streamwisc pressurc gradient causcd by increasing cross-sectional area can lcad to flow separation. Previous experimental studies of S-duct and transition duct flows have included Refs. 1, 2 and Refs. 3, 4, respectively. Vortex pairs have been observed in the exit planes of both duct types. These vortices are duc to secondary flows induced by pressure gradients resulting from streamline curvature. Regions of low total pressure are produced when the vortices convect boundary layer fluid into the main flow. The purpose of the present study is to predict the measured flow field in a diffusing $S$-duct and a circular-to-rectangular transition duct with a full Navicr-Stokes computer program, PARC3D, and to compare the numerical predictions with new detailed experimental measurements. The work was undertaken to extend previous studies and to provide additional CFD validation data necded to help model flows with strong secondary flow and boundary layer separation. The S-duct computation extends the study of Smith et al. ${ }^{5}$ and Harloff et al. ${ }^{6}$ which concluded that the computation might be improved by using a finer grid and more advanced turbulence models. The present study compares results for both the Baldwin-Lomas and $k-\varepsilon$ turbulenee models and is conducled with a refined grid. For the transition duct, two inlet conditions were considered, the first with straight flow and the second with swirling flow. The first case permits examination of the effects of the geometric transition on the flow ficld, while the second case includes the rotational flow effect characteristic of a gas turbint engine.

\section{SUBJECT TERMS}

Computational fluid dynamics; Inlet flow; Intake systems; Engine inlets

15. NUMBER OF PAGES

\begin{tabular}{l|c}
\hline 17. SECURITY CLASSIFICATION \\
$\begin{array}{c}\text { OF REPORT } \\
\text { Unclassified }\end{array}$ & $\begin{array}{c}\text { 18. SECURITY CLASSIFICATION } \\
\text { OF THIS PAGE } \\
\text { Unclassified }\end{array}$
\end{tabular}

19. SECURTYY CLASSIFICATION OF ABSTRACT

20. LIMITATION OF ABSTRACT

Unclassified

Unclassified 